\title{
Identification of homogeneous precipitation regions via Fuzzy c-means in the hydrographic region of Tocantins-Araguaia of Brazilian Amazonia
}

\author{
Evanice Pinheiro Gomes ${ }^{1}\left[\right.$ ] Claudio José Cavalcante Blanco ${ }^{2} \cdot$ Francisco Carlos Lira Pessoa $^{2}$
}

Received: 17 October 2017 / Accepted: 29 November 2018 / Published online: 8 December 2018

(c) The Author(s) 2018

\begin{abstract}
Determination of homogeneous regions of precipitation is a major step towards obtaining regional rainfall patterns, which are models for the estimation of total rainfall used in water resources engineering. In this study, homogeneous regions of precipitation were identified within the Hydrographic Region of Tocantins-Araguaia (HRTA) of Brazilian Amazonia. This hydrographic basin is of great importance for Brazil because it has been exploited for the production of hydropower since the 1970s. Currently it is a border of the agribusiness of the country. Therefore, it is important to know the rainfall regime of the region. Thus, three homogeneous regions of precipitation were delimited using the Fuzzy c-means method and physicalclimatic variables such as location (latitude and longitude), altitude, and precipitation. These regions were also tested and confirmed for their homogeneity using the Heterogeneity Test $H$. The values of total precipitation found for the regions are consistent with the volume of precipitation recorded in the analysed region and that found in the literature. The formation of these regions, in addition to contributing to the understanding of the hydrological behaviour, will aid in studies of the regionalization of rainfall in the region.
\end{abstract}

Keywords Physical-climatic variables $\cdot P B M$ index $\cdot$ Heterogeneity Test $H$

\section{Introduction}

The knowledge of hydrological variables is indispensable for the management of water resources. Among the hydrological variables, precipitation is one of the most important variable. For example, its scarcity affects uses such as irrigation and public supply. Already their surplus can generate floods and erosion of the soil, damaging, respectively, cities and the use of the soil. However, one of the problems presented in precipitation studies is the lack of monitoring and

Claudio José Cavalcante Blanco

blanco@ufpa.br

Evanice Pinheiro Gomes

gomesevanice@ufpa.br

Francisco Carlos Lira Pessoa

fclpessoa@ufpa.br

1 Post-Graduation Program of Civil Engineering, Federal University of Pará - PPGEC/ITEC/UFPA, Belém, Brazil

2 School of Environmental and Sanitary Engineering, Federal University of Pará - FAESA/ITEC/UFPA, Belém, Brazil temporal and spatial information on precipitation. This problem greatly affects the planning and management of water resources, especially in irrigation projects, supply reservoirs, urban drainage design and flood control systems, which need knowledge of precipitation to be planned and operated efficiently, guaranteeing essential services to the population.

In order to obtain information on rainfall in a river basin, researchers have sought techniques to explore existing rainfall data in certain parts of a basin and estimate it for areas in need or lack of hydrological information. In this context, the formation of homogeneous regions of precipitation is a tool capable of providing the spatial and temporal behaviour of precipitation. The term homogeneous regions are associated with regions that have hydrological similarity (Patil and Stieglitz 2011; Wazneh et al. 2013; Swain et al. 2016).

In this context, the Fuzzy c-means method has presented good results in the formation of regional clusters, as, for example, in the studies developed by Dikbas et al. (2011). These authors compared the Fuzzy c-means and k-means clustering methods and noted that the Fuzzy c-means method was the best for homogeneous region formation. Sadri and Burn (2011) adopted the L-moment statistic and 
the Fuzzy c-means method for the formation of homogeneous regions of precipitation in the Canadian provinces of Alberta, Saskatchewan, and Manitoba. Satyanarayana and Srinivas (2011) were able to identify and regionalize twenty-four homogeneous precipitation clusters throughout the Chinese territory using the Fuzzy c-means method. Farsadnia et al. (2014) adopted the self-organizing feature map (SOFM) method, along with the Fuzzy c-means, K-means, and Ward methods to identify homogeneous regions of precipitation in Mazandaran Province of northern Iran. Goyal and Gupta (2014) compared the Fuzzy c-means and k-means methods in the definition of homogeneous regions of precipitation in Northeast India and concluded that the Fuzzy c-means method presented better results in the formation of regions.

Existing precipitation studies, carried out by Brazilian Agricultural Research Corporation-EMBRAPA (1994), by the National Water Agency-ANA (2009) and by Loureiro et al. (2015), which adopted geostatistical interpolation in the region, characterized the precipitation, considering only the behaviour of the historical series and identified that the total rainfall decreases in the north-south direction. However, the formation of homogeneous regions by the fuzzy group c-means taking in account the series of precipitation, geographic, and climatic characteristics of the basin, making this method complete, since the precipitation is influenced by several climatic elements, such as altitude and the geographic position, which were adopted in this study. In relation to the formation of homogeneous regions, comparing to other methods, the Fuzzy c-means is based on the concept of pertinence, identifying homogeneous regions with less subjectivity than other methods.

The Hydrographic Region of Tocantins-AraguaiaHRTA is of great importance for Brazil due the hydroelectric production. In addition to hydroelectric potential, the region has excelled in mining, agroindustry, agriculture, and livestock, and especially in irrigation projects for corn, rice, and soybeans. EMBRAPA (2014) registered 109.5 thousand hectares of irrigable areas in the region. Thus, the objective of the paper is to identify homogeneous regions of precipitation in the HRTA, using Fuzzy c-means method, showing the spatial variability of annual rainfall totals in the region. These results can be used by society towards a more sustainable use of water resources, especially for this region, which has a big demand for water resources.

\section{Materials and methods}

\section{Study area}

The region lies between the south parallel $0^{\circ} 30^{\prime}$ and $18^{\circ} 05^{\prime}$ and the longitude meridians $45^{\circ} 45^{\prime}$ and $56^{\circ} 20^{\prime}$. Its configuration is elongated, with a South-North direction, following the predominant direction of the main watercourses, the Tocantins and Araguaia rivers. The total drainage area of the HRTA is $918.822 \mathrm{~km}^{2}$ and covers part of the Midwest, North and North-east regions of Brazil. This region has a tropical climate, with an average annual temperature of $26^{\circ} \mathrm{C}$, and two well-defined climatic periods: rainy, from October to April, with more than $90 \%$ precipitation, with the existence of some dry days between January and February, forming the so-called summer; and dry matter, from May to September, with low relative humidity. The water balance of the region estimates that the average annual precipitation is of the order of $1.837 \mathrm{~mm}$ and the flow is of $13.624 \mathrm{~m}^{3} / \mathrm{s}$ and the actual evapotranspiration is $1.371 \mathrm{~mm}$, which represents $75 \%$ of the precipitation, while the annual average real evapotranspiration of the country is $1.134 \mathrm{~mm}$ or $63 \%$ of the precipitation, and the mean coefficient of surface flow is 0.30 (National Water Agency (ANA) 2009). Figure 1 presents that HRTA is divided into three sub-basins: Alto Tocantins (ATO), Baixo Tocantins (BTO), and Araguaia (ARA). This figure also shows the use and occupation of soil, indicating strong anthropic action and the use of water resources mainly destined to hydroelectric production. Thus, the hydrographic basin is of great importance for Brazil, since its source has been exploited for the production of hydropower since the 1970s and has not yet been exhausted. Tucuruí Hydroelectric Power Plant, located in the state of Pará, is a large-scale hydroelectric power plant. In addition to hydroelectric potential, the region has excelled in mining, agroindustry, agriculture, and livestock, and especially in irrigation projects for corn, rice, and soybeans. According to the monitoring carried out by the Brazilian Agricultural Research Company-EMBRAPA, 109.5 thousand hectares of irrigable areas were registered in this region in 2014. The activities of land use and occupation are divided into urbanized areas of crops, of agroforestry systems, pastures, and agricultural establishments.

\section{Data sources}

Historical series of rainfall amounts were adopted from 83 rainfall gauge station of the National Water Agency (ANA) database in HRTA (Fig. 1). The rainy seasons were chosen based on the historical series of data, opting for the stations with a larger series of data that were consistent and without observation failures. Of the 83 stations adopted, 70 had series with 30 years of data (1975-2004) and 13 stations had series ranging from 17 to 28 years (1977-2004). These series were organized in a database, which includes calculations for the average annual precipitation of each station. Information on altitude and geographic location was also extracted from the ANA database. The mean annual precipitation (MAP), altitude, latitude and longitude were used were used to apply the 
Fig. 1 Hydrographic region of Tocantins-Araguaia (HRTA)

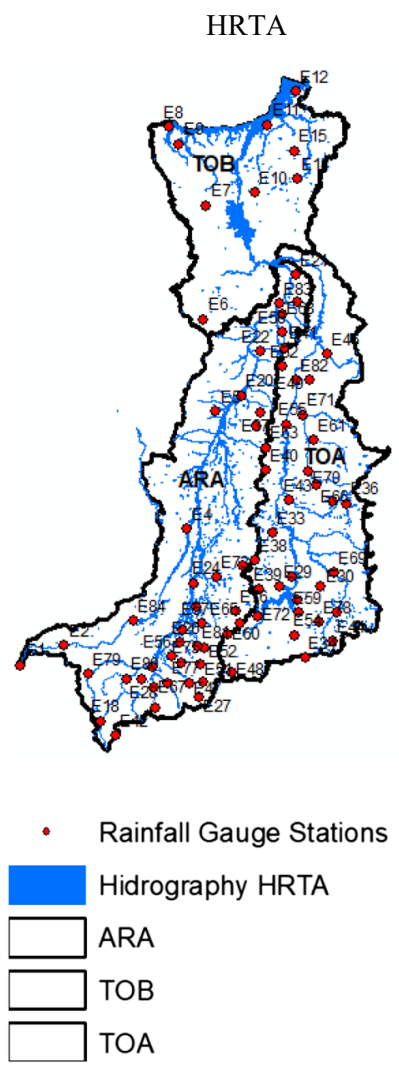

Use and occupation of soil

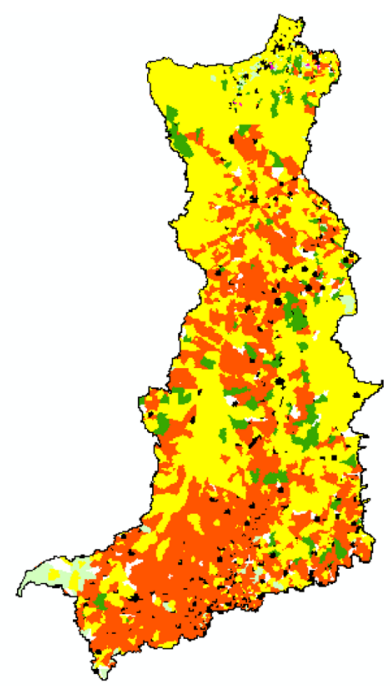

Tillage

3 Woods and/or florests

Grasslands

C. Agroforests Systems

03 Area with agriculture

3 Urbanized Area
Use of water resources

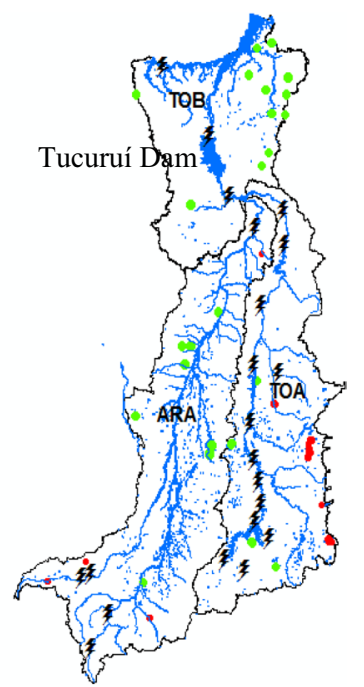

Dam

Reservoirs

Small power plants

4 HPP

Fuzzy c-means method and thus identify the homogeneous regions of precipitation. Table 1 shows the rainfall gauge stations and variables used in this study.

\section{Fuzzy c-means}

In the Fuzzy c-means clustering, the partitions were generated by minimizing a function, equated by an iterative algorithm (FCM), indicating the degree of membership of an element belonging to a particular cluster. Therefore, it is a technique in which each element belongs to a cluster with a certain degree of pertinence. The technique required prespecifications of the number of clusters to be formed. The Fuzzy c-means cluster looks for the partition that minimizes the objective function, as represented by Eq. 1 .

$J=\sum_{i=l}^{n} \sum_{j=l}^{p}\left(u_{i j}\right)^{m} d\left(X_{i}, C_{j}\right)^{2}$,

where $n$ is the number of data; $p$ is the number of clusters; $u_{i j}$ is the degree of relevance of the sample $X_{i}$ to the $j$-th cluster; $m$ is the fuzziness parameter; $d$ is the Euclidean distance between $X_{i}$ and $C_{j} ; X_{i}$ is the data vector, with $i=1,2, \ldots, n$, representing a data attribute; and $C_{j}$ is the centre of a fuzzy clustering. The objective function $J$ is minimized, and the membership degrees $u_{i j}$ are generated according to Eq. 2 .

$u_{i j}=\left[\sum_{k=l}^{c}\left(\frac{d\left(X_{i}, C_{j}\right)}{d\left(X_{i}, C_{j}\right)}\right)^{2 /(m-1)}\right]$

where $C_{j}$ can be obtained by Eq. 3 .

$C_{j}=\frac{\sum_{j=l}^{n}\left(u_{i j}\right)^{m} X_{i}}{\sum_{j=l}^{n}\left(u_{i j}\right)^{m}}$

The degrees of membership $u_{i j}$, representing the probabilities, are generated from a uniform distribution in the interval $[0,1]$. The clusterings are modified at each iteration following the algorithm (Fig. 2).

The fuzziness parameter $(m)$ is also known as the Fuzzy weight exponent and is a parameter that controls the level of diffusivity in the classification process. Thus, for $m=1$, the clusters have strict limits equivalent to those of the k-means and, as the value increases, the boundaries become more diffuse. According to Cox (2005), $m$ is usually in the range of 1.25-2.0. The cluster decision is defined by the greater degree of relevance presented for each element analysed. Thus, for a given $X_{i}$, its greater degree of pertinence will determine to which cluster this $X_{i}$ belongs, which clusters all the data and avoids equivocations and rigidity in the formation of the clusterings. 
Table 1 Rainfall gauge stations and variables used in this study

\begin{tabular}{|c|c|c|c|c|c|}
\hline ID & Stations & MAP (mm) & Altitude (m) & Latitude & Longitude \\
\hline E1 & São José da Serra & 1613.78 & 797 & -15.836 & -55.322 \\
\hline E2 & Rio das Mortes & 1689.70 & 551 & -15.315 & -54.176 \\
\hline E3 & Alô Brasil & 1657.61 & 339 & -12.164 & -51.697 \\
\hline E4 & Santo Antonio Leverger & 1581.00 & 205 & -12.292 & -50.963 \\
\hline E5 & Barreira do Campo & 1417.30 & 195 & -9.228 & -50.211 \\
\hline E6 & Fazenda Caiçara & 1730.10 & 95 & -6.815 & -50.539 \\
\hline E7 & Faz. Estrela Norte & 1931.40 & 22 & -3.854 & -50.463 \\
\hline E8 & Acampamento IBDF & 2011.56 & 11 & -1.792 & -51.434 \\
\hline E9 & Maracacuera Florestal & 2619.68 & 20 & -2.245 & -51.179 \\
\hline E10 & Cachoeira Tracambeua & 2381.51 & 50 & -3.510 & -49.209 \\
\hline E11 & Abaetetuba & 2583.90 & 13 & -1.738 & -48.859 \\
\hline E12 & Vigia & 2843.30 & 15 & -0.868 & -48.110 \\
\hline E13 & Faz. Maringa & 1933.30 & 20 & -3.161 & -48.100 \\
\hline E14 & Tomé-Açu & 2552.80 & 45 & -2.421 & -48.149 \\
\hline E15 & Abreulandia & 2117.39 & 240 & -9.624 & -49.155 \\
\hline E16 & Almas & 1524.14 & 427 & -11.579 & -47.174 \\
\hline E17 & Alto Araguaia & 1681.33 & 659 & -17.300 & -53.219 \\
\hline E18 & Ananas & 1561.50 & 191 & -6.364 & -48.073 \\
\hline E19 & Araguacema & 2048.03 & 203 & -8.810 & -49.556 \\
\hline E20 & Araguatins & 1551.70 & 122 & -5.648 & -48.125 \\
\hline E21 & Arapoema & 1866.98 & 215 & -7.659 & -49.065 \\
\hline E22 & Aruanã & 1536.86 & 200 & -14.927 & -51.081 \\
\hline E23 & Bandeirantes & 1456.25 & 276 & -13.698 & -50.800 \\
\hline E24 & Bom Jardim de Goiás & 1649.99 & 402 & -16.209 & -52.169 \\
\hline E25 & Britânia & 1416.60 & 297 & -15.246 & -51.163 \\
\hline E26 & Cachoeira GO & 1513.54 & 766 & -16.669 & -50.649 \\
\hline E27 & Caiaponia & 1631.64 & 713 & -16.949 & -51.811 \\
\hline E28 & Campinaçu & 2441.46 & 683 & -13.790 & -48.567 \\
\hline E29 & Cavalcante & 1849.89 & 821 & -13.797 & -47.462 \\
\hline E30 & Colinas do Sul & 1573.37 & 530 & -14.151 & -48.078 \\
\hline E31 & Colinas TO & 1801.25 & 229 & -8.053 & -48.482 \\
\hline E32 & Colonha & 1419.70 & 264 & -12.388 & -48.711 \\
\hline E33 & Contagem & 1570.26 & 1242 & -15.653 & -47.878 \\
\hline E34 & Córrego do ouro & 1544.32 & 569 & -16.298 & -50.557 \\
\hline E35 & Dianópolis & 1449.21 & 679 & -11.625 & -46.811 \\
\hline E36 & Dois Irmãos Tocantins & 2028.89 & 264 & -9.257 & -49.064 \\
\hline E37 & Entroncamento S M & 1634.60 & 345 & -13.103 & -49.201 \\
\hline E38 & Estrela do Norte & 1750.67 & 467 & -13.873 & -49.071 \\
\hline E39 & Fátima & 1897.41 & 352 & -10.764 & -48.902 \\
\hline $\mathrm{E} 40$ & Faz Primavera & 1816.08 & 257 & -7.559 & -48.421 \\
\hline E41 & Faz São Bernardo & 1674.44 & 750 & -17.680 & -52.833 \\
\hline $\mathrm{E} 42$ & Faz. Lobeira & 1556.30 & 243 & -11.531 & -48.292 \\
\hline E43 & Faz. Santa sé & 1684.06 & 573 & -15.216 & -47.157 \\
\hline E44 & Flores GO & 1144.44 & 200 & -14.450 & -47.045 \\
\hline E45 & Goiantins & 1572.48 & 185 & -7.711 & -47.315 \\
\hline E46 & Israelândia & 1597.32 & 406 & -16.300 & -50.906 \\
\hline E47 & Itaberaí & 1827.62 & 726 & -16.030 & -49.800 \\
\hline E48 & Itacaja & 1844.53 & 250 & -8.392 & -47.763 \\
\hline E49 & Itapirapua & 1589.17 & 343 & -15.816 & -50.609 \\
\hline E50 & Itapuranga & 1644.69 & 646 & -15.816 & -50.608 \\
\hline E51 & Jeroaquara & 1779.80 & 400 & -15.373 & -50.500 \\
\hline
\end{tabular}


Table 1 (continued)

\begin{tabular}{|c|c|c|c|c|c|}
\hline ID & Stations & MAP (mm) & Altitude (m) & Latitude & Longitude \\
\hline E52 & Lagoa da Flexa & 1436.41 & 200 & -14.333 & -50.730 \\
\hline E53 & Mimoso & 1307.59 & 687 & -15.058 & -48.159 \\
\hline E54 & Miracema Tocantins & 1706.89 & 210 & -9.564 & -48.388 \\
\hline E55 & Monte Carlos GO & 1542.97 & 400 & -15.606 & -51.357 \\
\hline E56 & Mozarlandia & 1654.07 & 400 & -14.741 & -50.577 \\
\hline E57 & Muricilandia & 1671.40 & 393 & -7.154 & -48.470 \\
\hline E58 & Niquelândia & 1703.61 & 568 & -14.475 & -48.041 \\
\hline E59 & Nova América & 1605.70 & 800 & -15.021 & -49.892 \\
\hline E60 & Novo Acordo & 1598.19 & 300 & -9.961 & -47.675 \\
\hline E61 & Novo Planalto & 1588.39 & 286 & -13.245 & -49.502 \\
\hline E62 & Paraíso do TO & 2280.65 & 390 & -10.165 & -48.891 \\
\hline E63 & Perez & 1499.26 & 299 & -15.890 & -51.853 \\
\hline E64 & Pilar de Goiás & 1948.00 & 765 & -14.761 & -49.580 \\
\hline E65 & Pindorama do Tocantins & 1614.57 & 444 & -11.140 & -47.576 \\
\hline E66 & Piranhas & 1582.92 & 356 & -16.423 & -51.823 \\
\hline E67 & Piraquê & 1760.80 & 184 & -6.672 & -48.470 \\
\hline E68 & Ponte Paranã & 1245.44 & 363 & -13.425 & -47.139 \\
\hline E69 & Porto Gilandia & 1656.37 & 220 & -10.786 & -47.800 \\
\hline E70 & Porto Real & 1599.03 & 200 & -9.307 & -47.929 \\
\hline E71 & Porto Uruaçu & 1468.39 & 572 & -14.555 & -49.139 \\
\hline E72 & Rio Pintado & 1443.73 & 200 & -13.529 & -50.188 \\
\hline E73 & Sama & 1410.71 & 375 & -13.533 & -48.227 \\
\hline E74 & Santa fé & 1614.51 & 400 & -15.767 & -51.104 \\
\hline E75 & Santa Terezinha GO & 1504.88 & 400 & -14.433 & -49.706 \\
\hline E76 & São Ferreira & 1673.12 & 361 & -16.306 & -51.471 \\
\hline E77 & São João Aliança & 1498.55 & 1009 & -14.707 & -47.524 \\
\hline E78 & Tesouro & 1714.94 & 389 & -16.078 & -53.549 \\
\hline E79 & Torixoreu & 1405.73 & 307 & -16.201 & -52.550 \\
\hline E80 & Travessão & 1516.55 & 450 & -15.369 & -50.705 \\
\hline E81 & Tupiratins & 1740.09 & 192 & -8.398 & -48.130 \\
\hline E82 & Xambioá & 1694.99 & 148 & -6.413 & -48.533 \\
\hline E83 & Xavantina & 1526.45 & 263 & -14.672 & -52.355 \\
\hline
\end{tabular}

\section{PBM validation index}

\section{Algorithm of the Fuzzy c-means method}

- Determine the value for $p$ (number of groups), $m$ (fuzziness parameter) and $\mathcal{E}$ (error);

-Initialize the centroids according to Equation 3;

-Initialize the iteration counter $t$ as $t=0$;

-Calculate the objective function $J$ by means of Equation 1;

-Calculate the degrees of membership according to Equation 2;

- Check the stop condition: $d\left(V_{t}, V_{t+1)} \leq \varepsilon\right)$;

- If stop condition $=$ false then repeat the previous steps; otherwise, finalize the algorithm.

Fig. 2 Structure of the Fuzzy c-means algorithm
One of the questions in a clustering analysis is the validation of the formed clusters. To achieve a good result, it is necessary to evaluate which partition is most suitable for the data and whether the partition generated by the algorithm is of good quality. To answer these questions, there are several validation indices in the literature, such as the $V_{\mathrm{PC}}$ and $V_{\mathrm{PE}}$ index (Bezdek 1981); the $V_{\mathrm{WPE}}$ index (Windhan 1981); the $V_{\text {MPC }}$ index (Fukwyama and Sugeno 1989) and the PBM index (Pakhira et al. 2004).

In this study, the PBM index was used to validate the clusters and assess both the distances between the clusters formed and those between the elements and the centres of the formed clusters, which makes the validation safer. According to Pakhira et al. (2004), the PBM index serves to validate the number of clusters or subsets formed from a 
dataset. This index is defined as the product of three factors (Eq. 4), of which maximization ensures that the partition has a small number of compact clusters with large separations between at least two.

$\operatorname{PBM}(k)=\left(\frac{1}{k} \cdot \frac{E_{1}}{E_{k}} \cdot D_{k}\right)^{2}$

where $k$ is the number of clusters.

The factor $E_{1}$ (Eq. 5) is the sum of the distances of each sample to the geometric centre of all samples $w_{0}$. This factor does not depend on the number of clusters.

$E_{1}=\sum_{t-1 \ldots n} d\left(x(t), W_{0}\right)$

The factor $E_{k}$ (Eq. 6) is the sum of the distances between the clusters of $K$ clusterings and is weighted by the corresponding relevance value of each sample to the cluster.

$E_{k}=\sum_{t=1 \ldots n} \sum_{i=1 \ldots k} u i(t) d\left(x(t), W_{i}\right)^{2}$

$D_{k}$ (Eq. 7) represents the maximum separation of each pair of clusterings.

$D_{k}=\max _{i, j=1 \ldots k}\left(d\left(w_{i}, w_{j}\right)\right)$

The procedure to calculate the PBM index can be described as follows:

1. Select the maximum number of clusters $\boldsymbol{M}$;

2. Calculate the factor $E_{1}$;

3. For $K=2$ to $K=M$, do:
a. Run the FCM algorithm;
b. Calculate the factors $E_{k}$ and $D_{k}$;
c. Calculate the PBM index (k).

4. Determine the best number of clusters $K$ (Eq. 8).

$$
K=\operatorname{maxarg}(\operatorname{PBM}(k))
$$

The PBM index is an optimization index, so to obtain the best partition, one must process the algorithm for several $K$ values and choose the one that results in the highest index value because the higher the PBM index, the better the partition (Pakhira et al. 2004).

\section{L-moments}

The L-moments make up a system of more reliable statistical measures for describing the characteristics of probability distributions and are derived from the probability-weighted moments (PWM) as generalized by Hosking and Wallis (1993). These moments are considered measures of the position, scale and shape of the probability distributions and are similar to conventional moments, but estimated by linear combinations (Eq. 9), asymmetry, kurtosis and the coefficient of variation.

$\beta_{r}=E\{X[F x(x)]\}$

where $\beta_{r}$ is the probability-weighted moment (PWM); $E$ is the probability of occurrence of the variable; and $F x(x)$ is the cumulative distribution function of $X$. According to Naghettini and Pintpo (2007), the estimation of $\beta_{r}$, from a finite sample of size $n$, begins with the ordering of its constituent elements in ascending order, that is, $X_{1}: n \leq X_{2}: n \leq \ldots X_{\mathrm{n}}$ : $\mathrm{n}$ and the values of the observed variable. Thus, the sample L-moments are calculated (Eqs. 10-13).

$\beta_{r}=\frac{1}{n} \sum_{j=r+1}^{n} \frac{(j-1)(j-2) \ldots(j-r)}{(n-1)(n-2) \ldots(n-r)} x_{j: n}$

$\beta_{0}=\frac{1}{n} \sum_{j=1}^{n} x_{j: n}$

$\beta_{1}=\frac{1}{n} \sum_{j=2}^{n} \frac{(j-1)}{(n-1)} \quad x_{j: n}$

$\beta_{2}=\frac{1}{n} \sum_{j=1}^{n} \frac{(j-1)(j-2)}{(n-1)(n-2)} x_{j: n}$

where $X_{j}$ represents the samples, and $n$ is the number of samples. These estimators serve to calculate the first four moments: $\lambda_{1}, \lambda_{2}, \lambda_{3}$, and $\lambda_{4}$, which are obtained using Eqs. $14,15,16$ and 17 , respectively.

$\lambda_{1}=\beta_{0}$

$\lambda_{2}=2 \beta_{1}-\beta_{0}$

$\lambda_{3}=6 \beta_{2}-6 \beta_{1}+\beta_{0}$

$\lambda_{4}=20 \beta_{3}-30 \beta_{2}+12 \beta_{1}-\beta_{0}$

Regarding shape measurements of distributions, it becomes more convenient for the L-moments to be expressed in dimensionless quantities. These quotients serve to determine the standard deviation of the homogeneous regions and are obtained using Eqs. 18-20.

$$
\begin{aligned}
& C v-L=\tau_{2}=\frac{\lambda_{2}}{\lambda_{1}} \\
& \gamma-L=\tau_{3}=\frac{\lambda_{3}}{\lambda_{2}}
\end{aligned}
$$


Fig. 3 PBM indices of the clusters

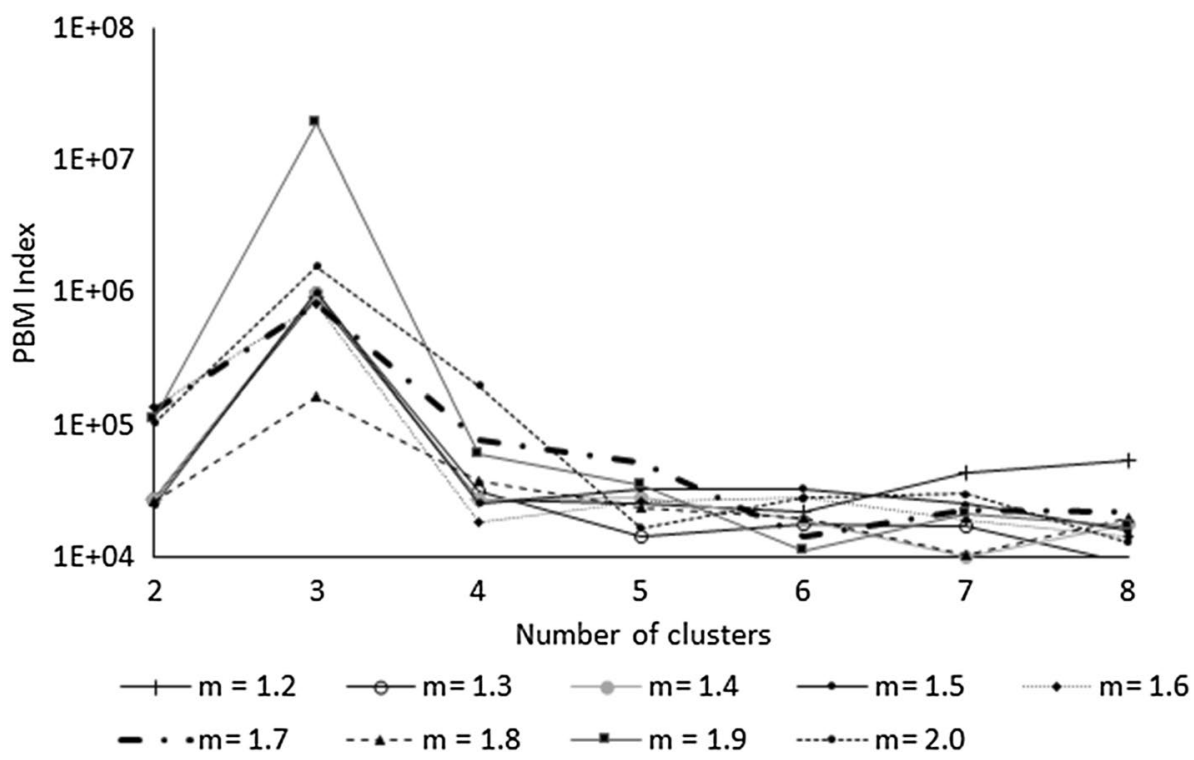

Table 2 Results of the application of the PBM index to the clusterings of the algorithm FCM

\begin{tabular}{cccccccccc}
\hline$p$ & $m=1.2$ & $m=1.3$ & $m=1.4$ & $m=1.5$ & $m=1.6$ & $m=1.7$ & $m=1.8$ & $m=1.9$ & $m=2.0$ \\
\hline 2 & $3 \mathrm{E}+04$ & $3 \mathrm{E}+04$ & $3 \mathrm{E}+04$ & $2 \mathrm{E}+04$ & $1 \mathrm{E}+05$ & $1 \mathrm{E}+05$ & $3 \mathrm{E}+04$ & $1 \mathrm{E}+05$ & $1 \mathrm{E}+05$ \\
3 & $9 \mathrm{E}+05$ & $1 \mathrm{E}+06$ & $1 \mathrm{E}+06$ & $1 \mathrm{E}+06$ & $8 \mathrm{E}+05$ & $8 \mathrm{E}+05$ & $2 \mathrm{E}+05$ & $\mathbf{2 E}+07$ & $2 \mathrm{E}+06$ \\
4 & $3 \mathrm{E}+04$ & $3 \mathrm{E}+04$ & $3 \mathrm{E}+04$ & $3 \mathrm{E}+04$ & $2 \mathrm{E}+04$ & $8 \mathrm{E}+04$ & $4 \mathrm{E}+04$ & $6 \mathrm{E}+04$ & $2 \mathrm{E}+05$ \\
5 & $3 \mathrm{E}+04$ & $1 \mathrm{E}+04$ & $3 \mathrm{E}+04$ & $3 \mathrm{E}+04$ & $3 \mathrm{E}+04$ & $5 \mathrm{E}+04$ & $2 \mathrm{E}+04$ & $3 \mathrm{E}+04$ & $2 \mathrm{E}+04$ \\
6 & $2 \mathrm{E}+04$ & $2 \mathrm{E}+04$ & $2 \mathrm{E}+04$ & $3 \mathrm{E}+04$ & $3 \mathrm{E}+04$ & $1 \mathrm{E}+04$ & $2 \mathrm{E}+04$ & $1 \mathrm{E}+04$ & $3 \mathrm{E}+04$ \\
7 & $4 \mathrm{E}+04$ & $2 \mathrm{E}+04$ & $1 \mathrm{E}+04$ & $3 \mathrm{E}+04$ & $2 \mathrm{E}+04$ & $2 \mathrm{E}+04$ & $1 \mathrm{E}+04$ & $2 \mathrm{E}+04$ & $3 \mathrm{E}+04$ \\
8 & $5 \mathrm{E}+04$ & $9 \mathrm{E}+03$ & $2 \mathrm{E}+04$ & $2 \mathrm{E}+04$ & $1 \mathrm{E}+04$ & $2 \mathrm{E}+04$ & $2 \mathrm{E}+04$ & $2 \mathrm{E}+04$ & $1 \mathrm{E}+04$ \\
\hline
\end{tabular}

$K-L=\tau_{4}=\frac{\lambda_{4}}{\lambda_{2}}$

The determination of the L-moments (MML) and L-moment quotients in hydrological studies of a given region can help in the treatment of data consistency, regional analysis and the identification of homogeneous regions. The advantage of this method is that it requires less computational effort to solve systems of equations (Naghettini and Pintpo 2007). The use of this methodology allows the use of the $\mathrm{H}$ test, which uses the L-moment quotients to test the homogeneity of regions classified as homogeneous.

\section{Heterogeneity Test H}

The measure of heterogeneity $H$ (Eq. 21), which is used in hydrology and meteorology, was proposed by Hosking and Wallis (1993) and aims to verify the degree of heterogeneity of a region by comparing the observed and expected variability of a homogeneous region based on L-statistics. This measure assists in determining the homogeneity of the regions formed in the cluster.
$H=\frac{\left(V-\mu_{v}\right)}{\sigma_{v}}$

where $V$ is the sample-weighted standard deviation for $C V-L$, $\mu_{v}$ is the arithmetic mean of the statistics $V_{j}$ obtained by simulation, and $\sigma_{v}$ is the standard deviation between the values of the dispersion measure of the simulated samples $\left(n_{\text {sim }}\right)$, which are obtained using Eqs. 22, 23 and 24, respectively.

$V=\left[\frac{\sum_{i=1}^{n} n_{i}\left(t^{i}-t^{R}\right)^{2}}{\sum_{i=1}^{n} n_{i}}\right]$

$\mu_{v}=\frac{\sum_{j=1}^{n_{\text {sim }}} V_{j}}{n_{\text {sim }}}$

$\sigma_{v}=\sqrt{\frac{\sum_{j=1}^{n_{\text {sim }}}\left(V_{j}-\mu_{v}\right)^{2}}{N_{\text {sim }}^{-1}}}$ 
Cluster 1

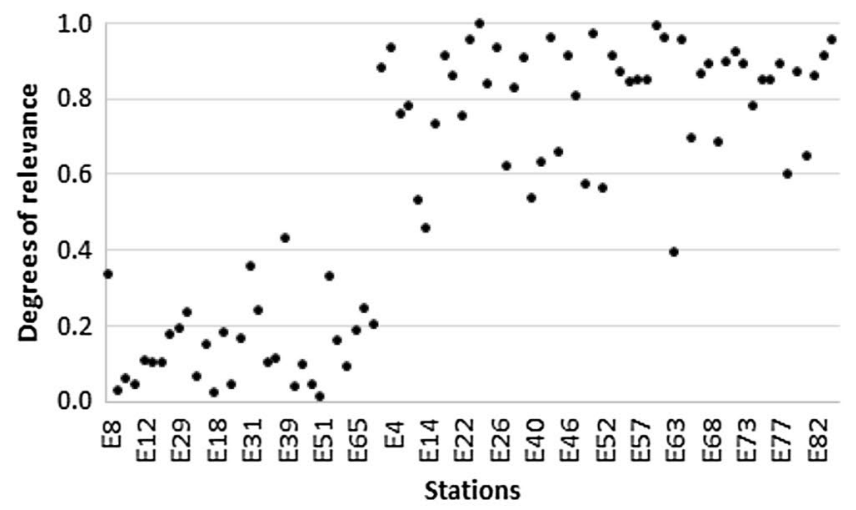

(a)
Cluster 2

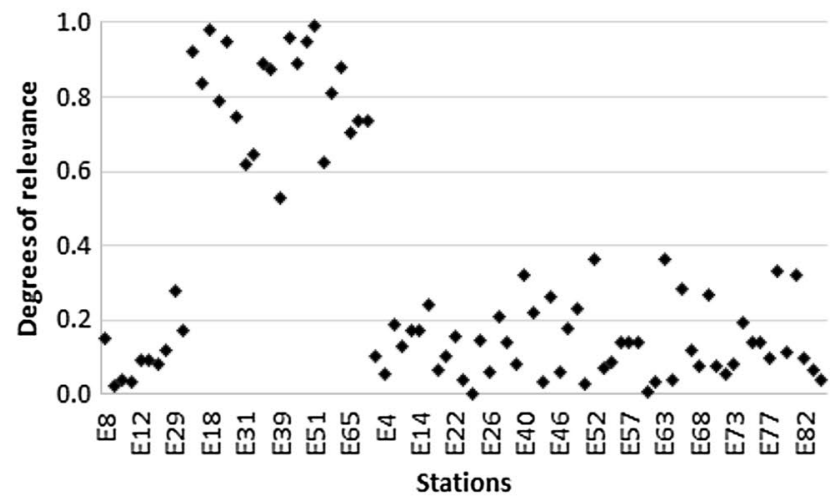

(b)

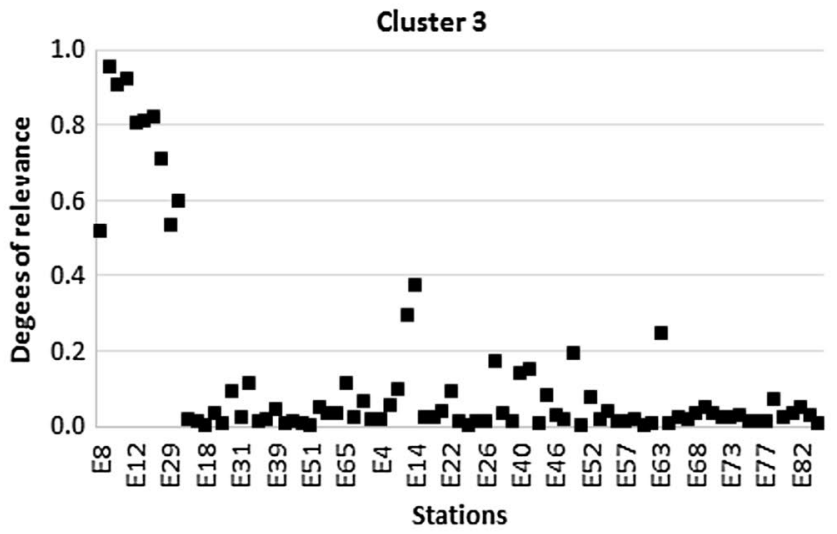

(c)

Fig. 4 Pertinence degrees of the stations by cluster

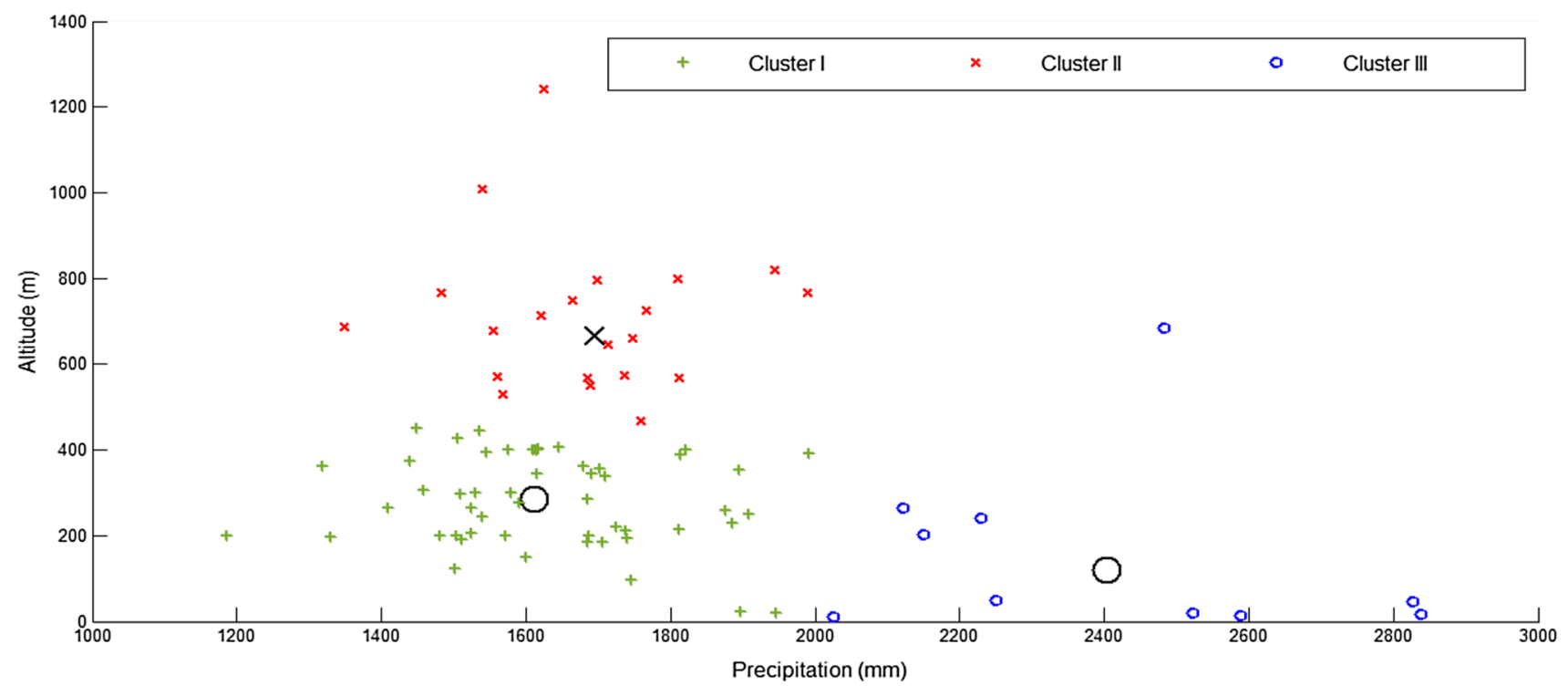

Fig. 5 Clusterings according to the precipitation and altitude characteristics 


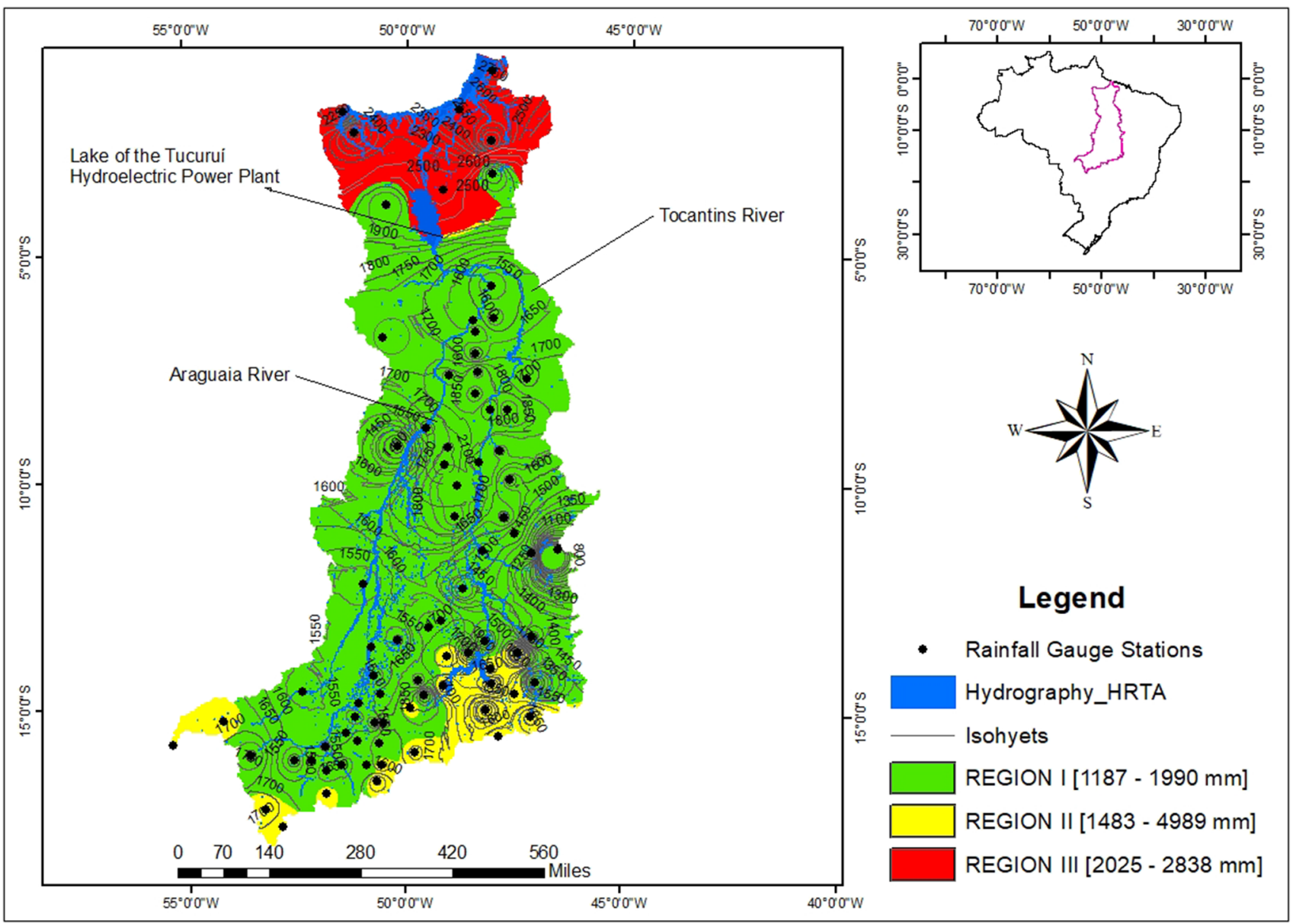

Fig. 6 Homogeneous regions of HRTA precipitation

The determination of $H$ starts with the calculation of the weighted standard deviation $V$ of $C V$ - Ls of the observed samples. Then, the simulation of the homogeneous region of precipitation is simulated from the adjusted Kappa distribution (Eq. 25), which obtains the quotients of regional L-moments. Next, the statistics $V_{j}\left(j=1,2, \ldots N_{\text {sim }}\right)$ are calculated (Eq. 23) for all homogeneous regions.

$F(x)=\left\{1-h\left[1-\frac{k(x-\xi)}{\alpha}\right]^{\frac{1}{k}}\right\}^{1 / h}$

Table 3 Average of L-moment quotients and the $\mathrm{H}$ value of the homogeneous regions

\begin{tabular}{llllr}
\hline Region & NS & $\begin{array}{l}\text { Average CV-L } \\
\text { Obs. }\end{array}$ & $\begin{array}{l}\text { Average CV-L } \\
\text { Sim. }\end{array}$ & \multicolumn{1}{l}{$H$} \\
\hline I & 52 & 0.1087 & 0.1075 & 0.0047 \\
II & 21 & 0.1134 & 0.1133 & -0.0049 \\
III & 10 & 0.1120 & 0.1125 & -0.7874 \\
\hline
\end{tabular}

where $x$ is the studied variable, $\xi$ is the position parameter, $\alpha$ is the scale parameter, and $k$ and $h$ are the shape parameters. According to the test of significance, which was proposed by Hosking and Wallis (1997), if $H<1$, the region is considered "acceptably homogeneous", if $1 \leq H<2$, the region is "possibly homogeneous," and finally, if $H \geq 2$, the region should be classified as "definitely heterogeneous".

\section{Results and discussion}

\section{Formation of homogeneous regions}

In total, 63 clusterings were performed by varying the fuzziness parameter from 1.2 to 2.0 and the number of clusters from 2 to 15 . However, it was verified that the larger the number of clusters, the smaller the value of the $P B M$ index. In this way, tests of up to 8 clusters were performed, ensuring the objectivity of the research, since the $P B M$ index would tend to decrease with clusters greater than 8 . The choice for the best cluster was determined by the $P B M$ index, which 


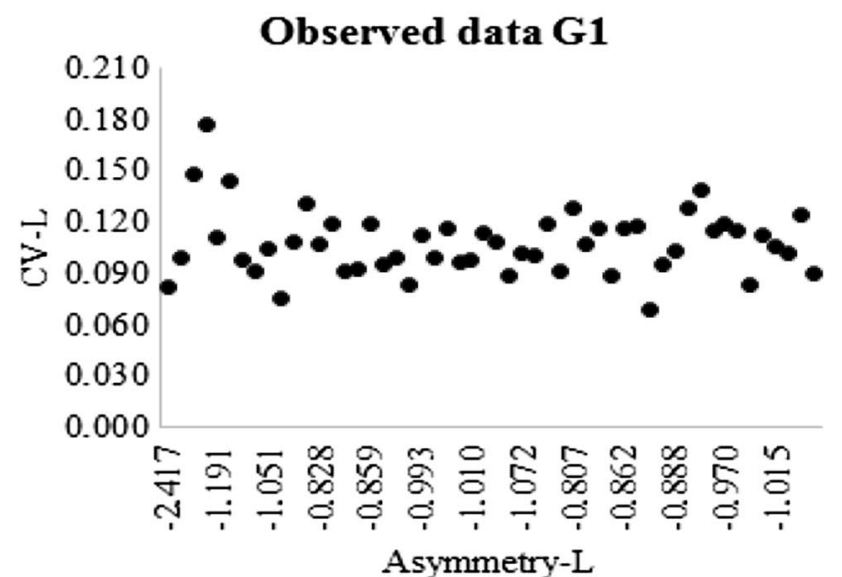

(a)
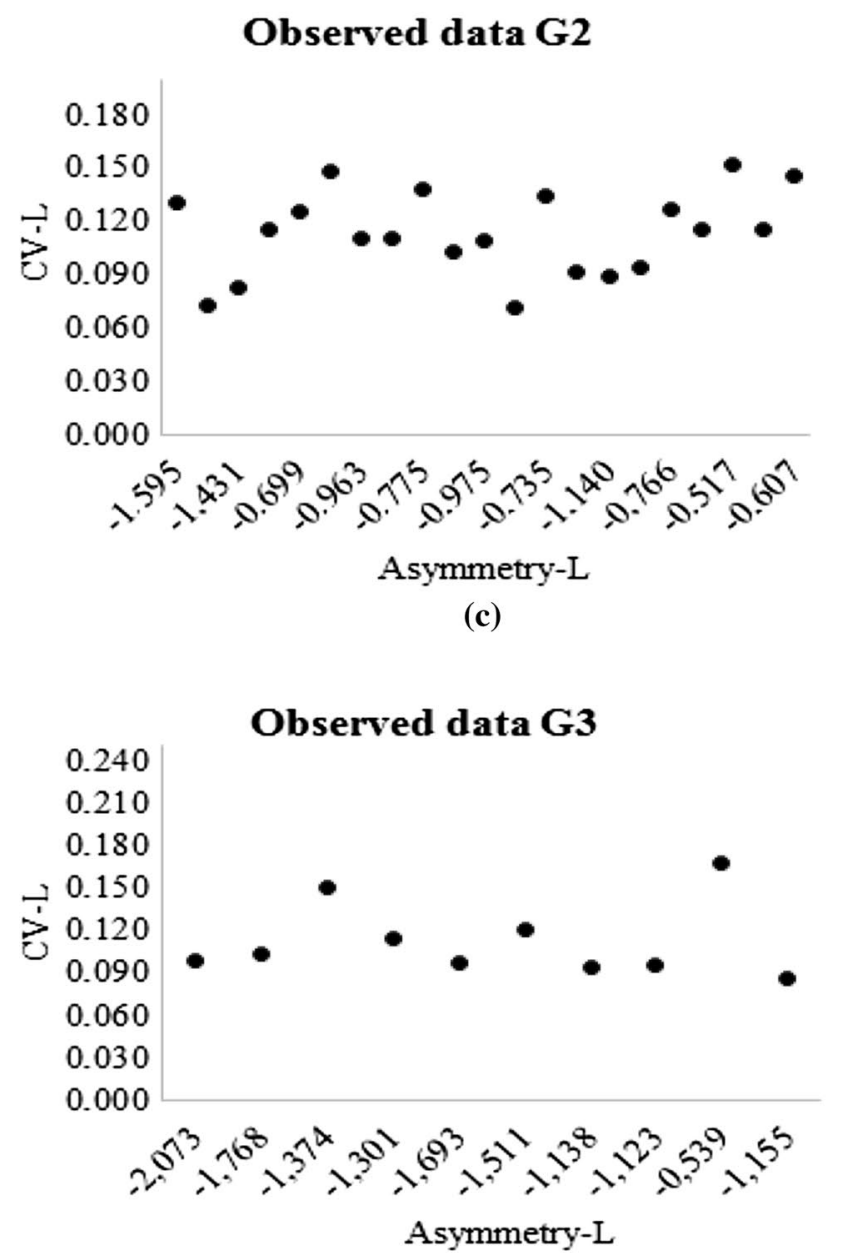

(e)

Fig. 7 Scatter plot of $C V$ - $L$ and $L$-Asymmetry quotients

presented a higher index (Fig. 3) in the formation of three clusters with a fuzziness parameter equal to 1.9 (Table 2).

One of the results from the FCM algorithm is the degree of the pertinence of the clustered elements. This degree of

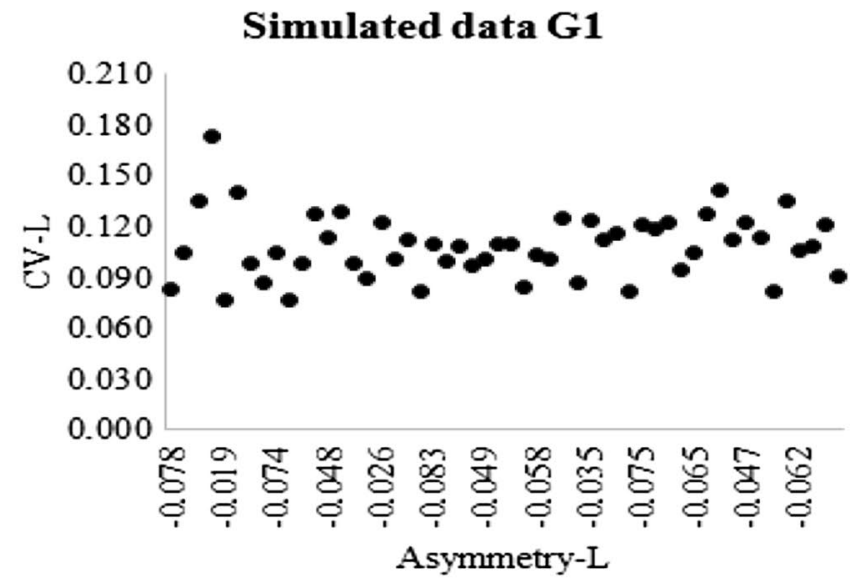

(b)

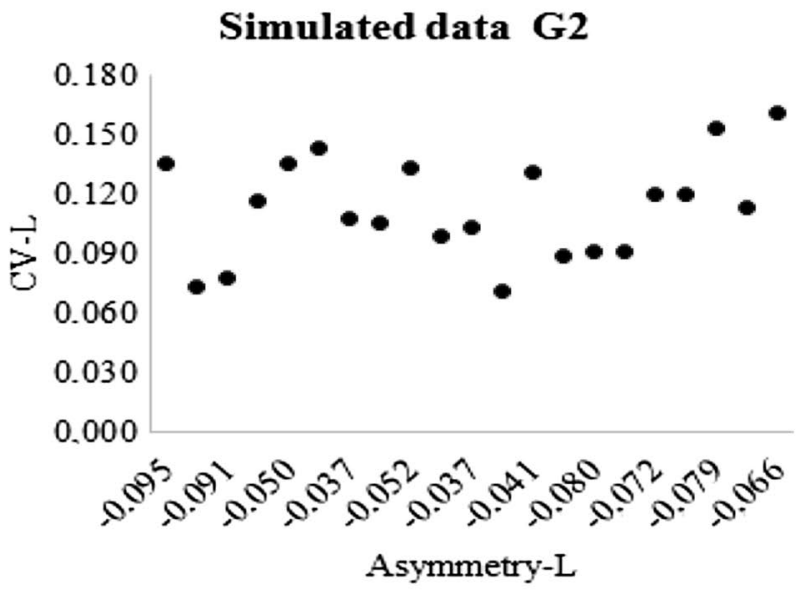

(d)

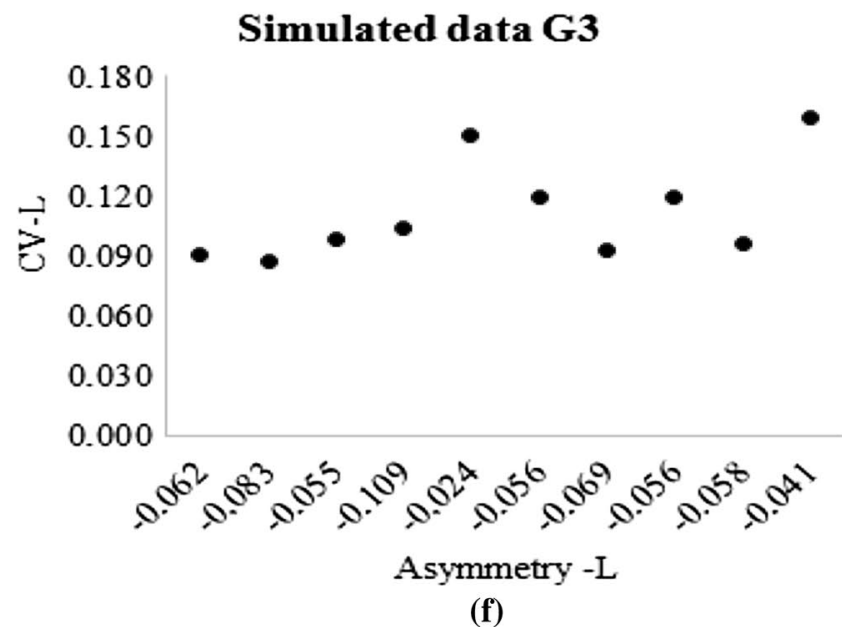

pertinence refers to the probability that an element belongs to a particular cluster. Thus, all of the rainfall gauge stations, which are represented by their characteristics of mean annual precipitation, altitude, and location, are presented a 
pertinence degree for each cluster. For example, the Acampamento IBDF Station (E8) has for Clusters 1, 2, and 3 a degree of pertinence of $0.34,0.15$, and 0.52 . According to Mingoti (2005), this station has an approximate 52\% probability of belonging to Cluster 3 . Thus, the decision to allocate the station to a given cluster is due to its degree of pertinence (Fig. 4).

The clusters formed represent the homogeneous regions of precipitation. Region I is formed by 52 stations, Region II is formed by 21 stations, and Region III is formed by 10 stations according to their pertinence degrees. In the formation of the clusters by the Fuzzy c-means, the rainfall stations are clustered considering the similarity between the elements of the cluster, according to the characteristics involved in the clustering analysis, in which each cluster has its clustering centre (Fig. 5).

Region I is formed by the rainfall stations with a mean of $1625 \mathrm{~mm}$, a minimum of $1187 \mathrm{~mm}$, and a maximum of $1990 \mathrm{~mm}$. These stations are concentrated in the central and south-western portion of the HRTA, specifically in the subbasins of Alto Tocantins and Araguaia, where the Cerrado biome dominates the tropical climate with a low rainfall index. Region II is formed by stations with average annual precipitations of approximately $1700 \mathrm{~mm}$, a minimum of $1349 \mathrm{~mm}$ and a maximum of $1989 \mathrm{~mm}$. Most of the stations in this cluster are distributed in the south and southeast portions of the HRTA. The predominant biome in this region is also the Cerrado. Region III is formed by stations that present higher volumes of precipitation, with an average of $2400 \mathrm{~mm}$, a minimum of $2025 \mathrm{~mm}$, and a maximum of $2843 \mathrm{~mm}$. The stations of this cluster are concentrated in the northern portion of the HRTA and in the region Baixo Tocantins, where the Amazonian biome predominates with a hot and humid climate and a high rainfall index (Fig. 6).

\section{Heterogeneity Test $\boldsymbol{H}$}

The calculation of the heterogeneity measure of the homogeneous regions was made by comparing the variances between the observed and simulated $C V$ - $L$. In this way, the heterogeneity measure is calculated according to Eq. 21 . In the verification of the Heterogeneity Test $H$, a value of $0.047,-0.0049$, and -0.7874 was obtained for Region I, Region II, and Region III, respectively (Table 3), which confers acceptably homogeneous regions, since all $H<1$.

The significance of the measure of heterogeneity can be visualized using the L-moment quotient diagrams (Fig. 7). In diagrams such as these, a possibly homogeneous region would have $C V$ - $L$ samples less dispersed than those obtained by simulation. In quantitative terms, this idea can be translated by the difference centred between the observed and simulated dispersions. The dispersion in the simulated regions, for the L-moment quotients, shows that there was no dispersion of the data, and, therefore, there are no stations with mean values much greater or less than the expected values. Thus, the simulated and observed dispersions are similar and form an acceptably homogeneous region.

\section{Conclusion}

The combined use of the Fuzzy c-means method, the PBM index, and the $H$ Heterogeneity Test was satisfactory for the formation and validation of homogeneous regions of precipitation. The satisfactory results of the application of the methodology were indicated by the formation of distinct clusters, with well-defined homogeneous regions, showing the spatial variability of annual rainfall totals in the region. In addition to contributing to the understanding of the hydrological behaviour of the region, the formation of these homogeneous regions of precipitation will aid in regionalization studies and support the management and planning of water resources in the Hydrographic Region of Tocantins-Araguaia-HRTA that is of great importance for Amazon and Brazil.

Acknowledgements The authors thank the National Council of Scientific and Technological Development (CNPq) for granting the Master's scholarship.

Open Access This article is distributed under the terms of the Creative Commons Attribution 4.0 International License (http://creativeco mmons.org/licenses/by/4.0/), which permits unrestricted use, distribution, and reproduction in any medium, provided you give appropriate credit to the original author(s) and the source, provide a link to the Creative Commons license, and indicate if changes were made.

\section{References}

Bezdek JC (1981) Modified objective function algorithms in pattern recognition with fuzzy objective function algorithms. Kluwer, Norwell

Brazilian Agricultural Research Corporation (EMBRAPA) (1994) National Center for Research of Cerrados-CPAC. Rainfall in the Cerrados. Brazilian Agricultural Research Corporation and National Center for Research of Cerrados, Brasília, Brazil (in Portuguese)

Brazilian Agricultural Research Corporation (EMBRAPA) (2014) Levantamento da agricultura irrigada por pivôs centrais no Brasil. Brazilian Agricultural Research Corporation, Brasília (um portuguese)

Cox E (2005) Fuzzy modeling and genetic algorithms for data mining and exploration, 1st ed. Elsevier/Morgan Kaufmann. Hardcover (Morgan Kaufmann series in data management systems)

Dikbas F, Firat M, Cok CA, Gungor M (2011) Classification of precipitation series using fuzzy cluster method. J Climatol 32:1596-1603

Farsadnia R, Kamrood RM, Nia MA, Rodarres R, Bray TM, Hand D, Sadatinejad J (2014) Identification of homogeneous regions for regionalization of watersheds by two-level self-organizing features maps. J Hydrol 509:387-397 
Fukwyama Y, Sugeno M (1989) A New method of choosing the number of clusters for the Fuzzy c-means method. In: Proceedings of fifth fuzzy systems symposium, pp 247-250

Goyal MK, Gupta V (2014) Identification of homogeneous rainfall regimes in northeast region of India using fuzzy cluster analysis. Water Resour Manag 28:4491-4511

Hosking J, Wallis J (1993) Some statistic useful in regional frequency analysis. Water Resour Res 29(2):271-281

Hosking J, Wallis J (1997) Regional frequency analysis: an approach based on L-moments, 1st edn. Cambridge University Press, New York

Loureiro GE, Fernandes LL, Ishihara JH (2015) Spatial and temporal variability of rainfall in the Tocantins-Araguaia hydrographic region. Acta sci Technol 37(1):89-98

Mingoti SA (2005) Data analysis using multivariate statistical methods (in Portuguese). Editora UFMG, Belo Horizonte (in portuguese)

Naghettini M, Pintpo EJA (2007) Hydrology Statistics, Ed. CPRM, Belo Horizonte, Brazil (in Portuguese)

National Water Agency (ANA) (2009) National water resources plan of the hydrographic region of Tocantins-Araguaia. National Water Agency, Brasília (in Portuguese)

Pakhira MK, Bandyopadhyay S, Maulik K (2004) Validity index for crisp and fuzzy clusters. Pattern Recognit 37:481-501
Patil S, Stieglitz M (2011) Hydrologic similarity among catchments under variable flow conditions. Hydrol Earth Syst Sci 15:989-997

Sadri S, Burn DH (2011) A fuzzy c-means approach for regionalization using a bivariate homogeneity and discordancy approach. J Hidrol 401:231-239

Satyanarayana P, Sirvinas VV (2011) Regionalization of precipitation in data sparse areas using large scale atmospheric variables-a fuzzy clustering approach. J Hydrol 405:462-473

Swain JB, Sahoo MM, Patra KC (2016) Homogeneous region determination using linear and nonlinear techniques. Phys Geogr 37(5):361-384

Wazneh H, Chebana F, Ouarda TBMJ (2013) Depth-based regional index-flood model. Water Resour Res 49:7957-7972

Windhan MP (1981) Cluster validity for fuzzy clustering algorithms. Fuzzy Sets Syst 5:177-185

Publisher's Note Springer Nature remains neutral with regard to jurisdictional claims in published maps and institutional affiliations. 